\title{
Tree die-off in response to global change- type drought: mortality insights from a decade of plant water potential measurements
}

\author{
David D Breshears ${ }^{1^{*}}$, Orrin B Myers ${ }^{2}$, Clifton W Meyer ${ }^{3}$, Fairley J Barnes ${ }^{3}$, Chris B Zou ${ }^{4}$, Craig D Allen ${ }^{5}$, \\ Nathan G McDowell ${ }^{3}$, and William T Pockman ${ }^{6}$
}

\begin{abstract}
Global climate change is projected to produce warmer, longer, and more frequent droughts, referred to here as "global change-type droughts", which have the potential to trigger widespread tree die-off. However, droughtinduced tree mortality cannot be predicted with confidence, because long-term field observations of plant water stress prior to, and culminating in, mortality are rare, precluding the development and testing of mechanisms. Here, we document plant water stress in two widely distributed, co-occurring species, piñon pine (Pinus edulis) and juniper (Juniperus monosperma), over more than a decade, leading up to regional-scale die-off of piñon pine trees in response to global change-related drought. Piñon leaf water potentials remained substantially below their zero carbon assimilation point for at least 10 months prior to dying, in contrast to those of juniper, which rarely dropped below their zero-assimilation point. These data suggest that piñon mortality was driven by protracted water stress, leading to carbon starvation and associated increases in susceptibility to other disturbances (eg bark beetles), a finding that should help to improve predictions of mortality during drought.
\end{abstract}

Front Ecol Environ 2009; 7(4): 185-189, doi:10.1890/080016 (published online 26 Aug 2008)

G lobal climate change is projected to produce warmer, longer, and more frequent droughts in many regions of the world (IPCC 2007) - referred to here and previously (Breshears et al. 2005) as "global change-type drought". Such drought can trigger high rates of tree mortality along elevation gradients (Gitlin et al. 2006; van Mantgem and Stephenson 2007) and can even drive regional-scale tree mortality of dominant vegetation (Breshears et al. 2005; Allen 2007). Regional-scale dieoff with such high rates of tree mortality will not only result in changes to vegetation structure, but will also impact land-surface interactions, land-surface stability, and ecosystem goods and services (MA 2005; NRC 2007). Notably, the relationship between the threshold for tree mortality and drought-induced water stress, which may also underlie the effects of biotic agents such as bark beetles (eg Shaw et al. 2005), is highly uncertain, and cannot be predicted confidently. This is, in large part, because long-term field observations of plant water

${ }^{1}$ School of Natural Resources, Institute for the Study of Planet Earth, and Department of Ecology and Evolutionary Biology, University of Arizona, Tucson, AZ *(daveb@email.arizona.edu); ${ }^{2}$ Division of Epidemiology and Biostatistics, University of New Mexico Health Sciences, Albuquerque, NM; ${ }^{3}$ Earth and Environmental Sciences Division, Los Alamos National Laboratory, Los Alamos, NM; ${ }^{4}$ School of Natural Resources, University of Arizona, Tucson, AZ; ${ }^{5}$ US Geological Survey, Jemez Mountains Field Station, Los Alamos, NM; ' ${ }^{6}$ Department of Biology, University of New Mexico, Albuquerque, NM stress prior to, and culminating in, mortality are essentially non-existent. Such observations are critically needed to improve assessments of ecological and landsurface changes due to tree die-off, which could occur in response to global warming (Breshears and Allen 2002; Breshears et al. 2005; MA 2005; IPCC 2007).

Many studies have considered tree mortality associated with drought, but observations of tree mortality in the field, obtained in combination with direct measurements of water stress leading up to widespread mortality, remain a critical gap for assessing physiological mechanisms that underlie drought-related tree mortality (McDowell et al. 2008). This gap is not directly addressed by existing studies, which for the most part quantify: (1) field mortality patterns, but lack concurrent data on plant water stress and other relevant physiological metrics; (2) physiological responses to drought in the field, but lack observations of tree mortality; or (3) physiological responses to simulated drought in the lab, but lack the conditions associated with development of drought stress and mortality in the field.

Stomatal regulation of transpiration provides plants with some control over the development of water potentials sufficient to induce transport failure via cavitation (spontaneous rupture of sap columns subjected to large negative pressure or tension; Sperry et al. 1998, 2002). As drought stress (measured as decreased plant water potential) develops, stomatal closure progressively restricts transpiration and, therefore, carbon assimilation. The water potential associated with zero carbon assimilation, 


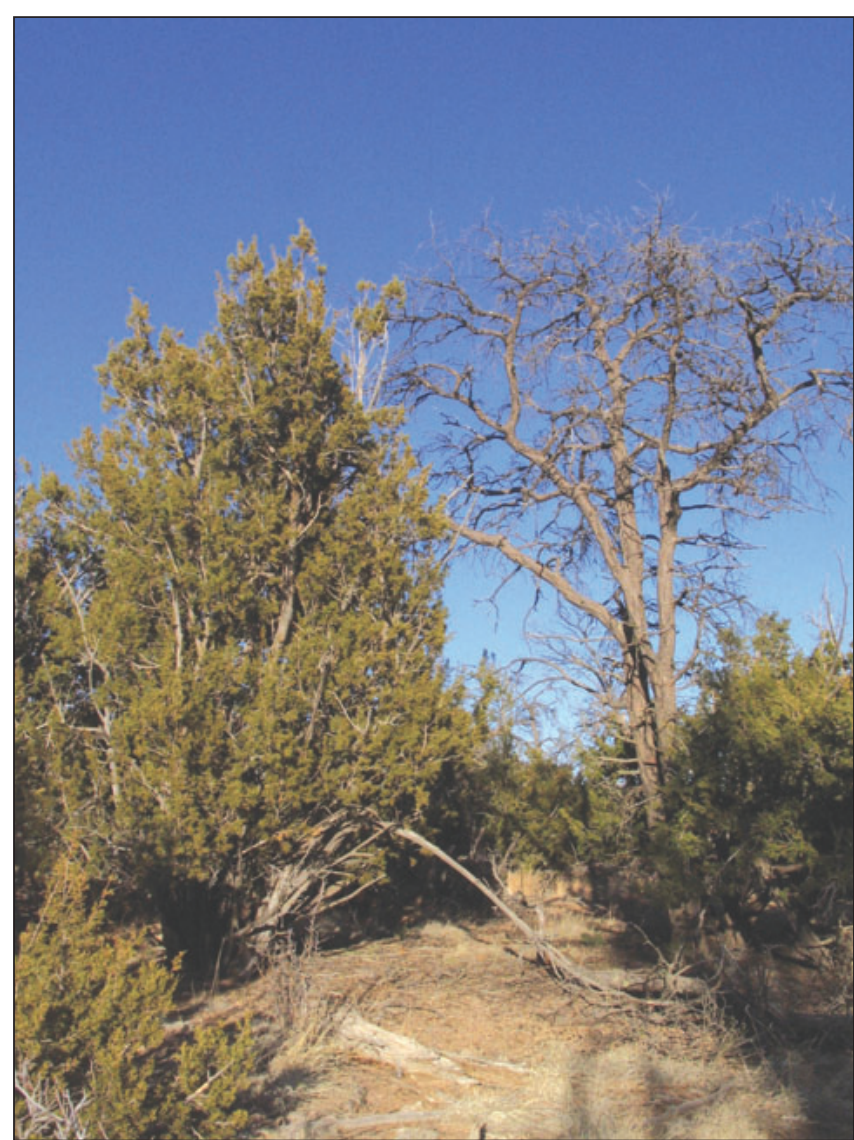

Figure 1. A semi-arid piñon-juniper woodland near Los Alamos, NM, after an unusually warm drought - a global change-type drought - resulted in mortality of piñon pine trees (Pinus edulis), while junipers (Juniperus monosperma) survived.

designated as the zero assimilation point (Lajtha and Barnes 1991), can be estimated from leaf-level measurements of gas exchange over a range of water potentials. If plant water potential remains at or below the zero assimilation point for a protracted period, metabolic depletion of carbon reserves should eventually lead to tree mortality (McDowell et al. 2008), even though stomatal closure has prevented transport failure.

As described above, our understanding of the mechanistic basis of tree mortality is limited by the availability of long-term water potential measurements that describe pre-drought variability and drought response of trees, particularly of species that exhibit differential mortality responses. Here, we report monthly, pre-dawn water potential in piñon and juniper individuals over more than a decade, a period that culminated in a severe drought across the southwestern US in 2000-2003. This drought was characterized by higher temperatures than a previous, severe drought event in the region during the 1950s, thereby representing a global change-type drought (Breshears et al. 2005). It also resulted in extensive mortality of a widely distributed tree species, piñon pine (Pinus edulis), while individuals of the co-occurring juniper species (Juniperus monosperma) largely survived (Breshears et al. 2005; Figure 1). The resultant mortality was of sufficient magnitude to transform landscapes (Figure 2) and highlights how the impacts of climate change may be driven by changes associated with events rather than by trends (Jentsch et al. 2007). We discuss insights revealed by the long-term plant water potential data and relate them to ongoing development of more mechanistic models for assessing vegetation die-off (McDowell et al. 2008).

\section{Methods}

The study was conducted at the Mesita del Buey site at Los Alamos National Laboratory, near Los Alamos, NM $\left(35.85^{\circ} \mathrm{N}, 106.27^{\circ} \mathrm{W}\right.$; Breshears 2008). The site is at an elevation of $2140 \mathrm{~m}$ and has an annual precipitation of $\sim 400 \mathrm{~mm}$, mainly in the form of winter snowfall and late-summer precipitation. Mean ambient air temperature is $\sim 9^{\circ} \mathrm{C}$, and ranges from $-2^{\circ} \mathrm{C}$ in January to $21^{\circ} \mathrm{C}$ in June, and soil depth varies between 33 to $125 \mathrm{~cm}$. Tree canopy cover prior to the mortality event was $\sim 50 \%$, divided roughly equally between $J$ monosperma and $P$ edulis (Breshears 2008). More than $90 \%$ of the piñons across the site died between 2002 and 2003, in response to the severe drought, whereas nearly all the junipers at the site survived (Breshears et al. 2005). Several species-specific physiological relationships (Lajtha and Barnes 1991) and patterns of root and foliar water uptake (Breshears et al. 1997; Breshears et al. 2008) have been quantified at this site, which aids in interpreting and extrapolating site observations (see references in Breshears 2008).

Pre-dawn plant water potentials were measured on five trees of each species, using standard methods (Breshears et al. 1997), approximately every 4 weeks from 1992 through the 2000-2003 drought, until after the death of all measured piñon trees. Measurements continued through mortality of piñon individuals, which occurred over a period of 11 months, beginning in August 2002 and ending in July 2003. After the initiation of the drought, individual piñon trees were evaluated every month, concurrently with plant water potential measurements, for signs of infestation by bark beetles (eg bore holes).

\section{Results}

Prior to the onset of the drought (March 1992-September 2001), long-term mean pre-dawn water potential for individual piñons averaged $-1.38 \mathrm{MPa}$ (mega-Pascals; individuals ranged from -1.33 to $-1.43 \mathrm{MPa}$; Figure 3$)$. During periods of severe drought (October 2001-December 2003), mean piñon water potential decreased to -2.35 $\mathrm{MPa}$ (with individual means ranging from -2.11 to -2.66 $\mathrm{MPa}$ ) and all measured piñons died after pre-dawn water potential remained below the zero assimilation point (Lajtha and Barnes 1991) continuously for at least 10 months (Figure 3). In contrast, all juniper trees studied survived the drought, with plant water potential only 

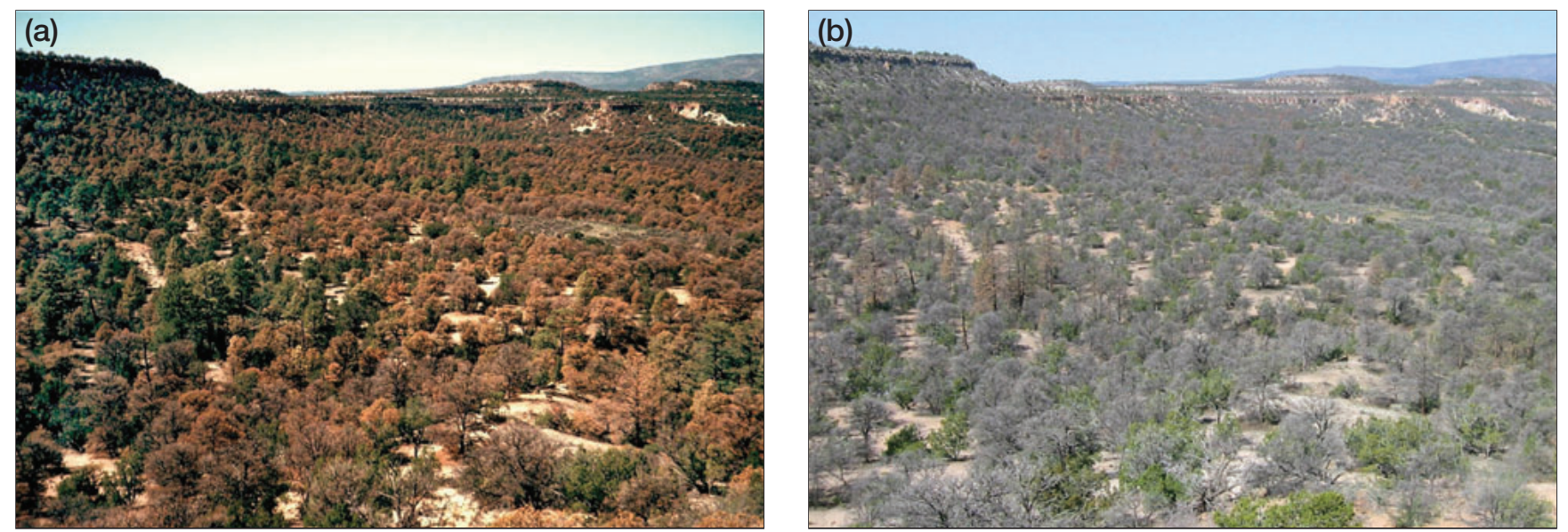

Figure 2. Landscape transformation associated with a die-off of piñon pine trees (Pinus edulis) triggered by a global change-type drought. Piñon pine trees, evergreen when alive, (a) exhibiting reddish-brown foliage indicating mortality (October 2002). (b) After they have lost their needles, exposed gray trunks of standing dead tree carcasses remain (May 2004). Almost all of the surviving green trees in (b) are junipers.

rarely falling below the zero assimilation point of -4.5 MPa (Lajtha and Barnes 1991), and never for longer than 4 months (Figure 3).

Several conditions characterized the lead-up to piñon mortality. In the decade prior to the onset of the drought, piñon trees recovered on nine separate occasions from a drop in water potential to below the species-specific zero assimilation point; these periods accounted for only $8-17 \%$ of the measurement dates and were never longer than 3-4 consecutive months. In contrast, beginning in October 2001, all five measured piñon trees had plant water potentials below the zero assimilation point for $57-100 \%$ of the remaining measurement dates up through mortality [mortality of the five individual trees occurred at 10, 14, 21, 22, and 22 months (respectively) after October 2001]. Water potentials for all five trees were below the zero assimilation point for at least a 10 -month consecutive period prior to mortality. Piñon trees exhibited signs of infestation by bark beetle (Ips confusus) only late in the 10 continuous months of water stress preceding mortality ( 8 months or later into that period), with infestation by bark beetles observed for all piñon individuals prior to mortality.

\section{Discussion}

Piñon mortality appears to result from protracted water stress that is of sufficient severity to constrain these trees below their zero carbon assimilation point. This prolonged period without carbon uptake may exhaust stored carbon reserves and predispose the trees to the effects of other stressors, such as bark beetles. The limitation of leaf-level gas exchange implicit in this phenomenon is consistent with stomatal regulation of gas exchange to avoid water transport failure (Sperry et al. 2002; McDowell et al. 2008). Piñon is regarded as isohydric (West et al. 2007), regulating transpiration to maintain a constant mid-day leaf water potential as soil water potential varies. With declining soil water potential, isohydric species limit transpiration to maintain relatively constant mid-day leaf water potential, which severely constrains carbon assimilation (Williams and Ehleringer 2000; McDowell et al. 2008). The widespread mortality observed after the water potential of the piñon trees dropped below their zero carbon assimilation value for more than 10 months contrasted with the recovery observed after 0-4-month periods of similar stress, and brackets the duration of drought that probably can be tolerated by piñon, potentially reflecting the longevity of stored energy resources.

Although juniper water potentials were frequently lower than those for piñon, juniper exhibits anisohydric behavior, allowing leaf water potential to decrease as soil water potential decreases. This stomatal behavior resulted in shorter periods where water potential was below the species-specific zero assimilation threshold for juniper. Juniper appears to be more drought tolerant than piñon, based on numerous physiological and morphological characteristics, including cavitation relationships (eg $100 \%$ stem cavitation occurs at about $-11 \mathrm{MPa}$ for juniper but at only about $-7 \mathrm{MPa}$ for piñon; Pockman et al. 1995; Linton et al. 1998; West et al. 2007). In addition, junipers are more drought tolerant with respect to transpiration and photosynthesis responses (Lajtha and Barnes 1991) and are even able to substantially reduce water stress through foliar absorption of intercepted rain (Breshears et al. 2008). The piñon mortality associated with protracted water stress was probably driven by carbon starvation (McDowell et al. 2008), although increased vulnerability to cavitation in xylem previously cavitated and refilled (so-called "cavitation fatigue"; Hacke et al. 2001) might also have contributed to mortality. The reported species-specific zero assimilation points, which were based on controlled phytotron (controlled growth chamber) experiments, are approximate but appear to be broadly applicable for both species on the basis of three other sets of observations. First, field mea- 


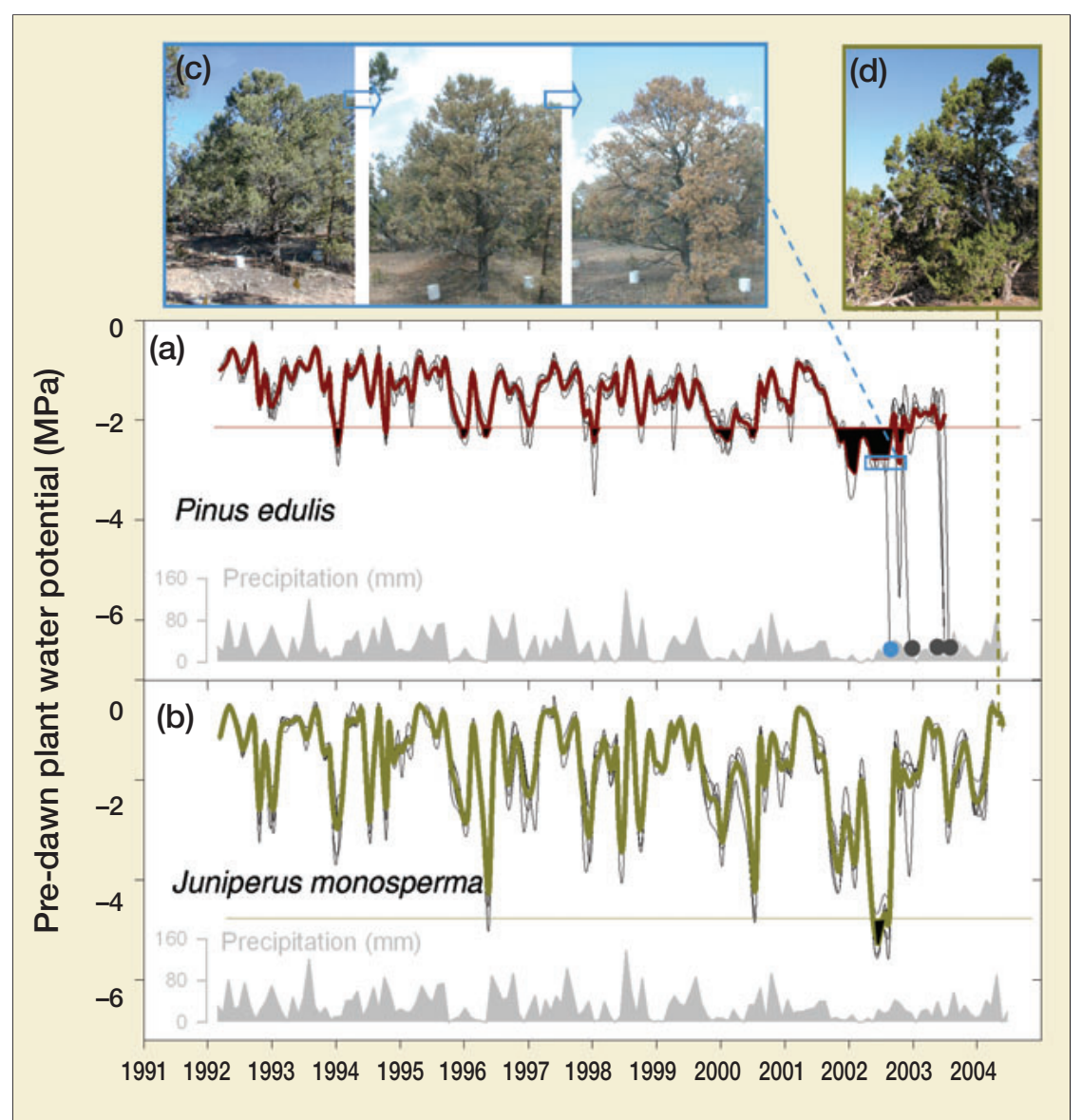

Figure 3. Pre-dawn plant water potential (more negative values indicate greater water stress) for (a) piñon (Pinus edulis; reddish-brown line) and (b) juniper (Juniperus monosperma; olive line). Thin, gray lines indicate individual trees, thick lines indicate species means of living trees, and shaded gray indicates monthly precipitation. (c) Foliar progression from dark green to pale green to brown for an individual piñon (May to August to October 2002, corresponding with blue inset box and blue mortality point in [a]; other piñon mortality points in dark gray); (d) junipers survived. Straight horizontal lines (color coded by species) are set at zero assimilation points for both piñon and juniper; black shaded areas below these lines highlight periods of accumulated water stress. tation data have been available in many previous studies (eg Allen and Breshears 1998). Furthermore, because the conditions leading up to the piñon mortality that we document are associated with global change-type drought, our results may be particularly relevant for projecting future changes in vegetation under a changing climate. A concurrently developed synthesis on the mechanisms of tree mortality, which highlights drought responses by piñon and juniper as a case study, proposes a broad framework for the roles of cavitation, protracted water stress, associated carbon starvation, and biotic agents (eg bark beetles) in contributing to speciesspecific responses associated with tree mortality (McDowell et al. 2008). Our results support a key prediction of that framework: that piñon mortality is driven by protracted water stress and carbon starvation caused by stomatal closure to avoid cavitation, rather than by uncontrolled and extensive cavitation alone. In highlighting the contrasting trajectories of water stress between cooccurring species that diverge in patterns of mortality and survival following global change-type drought, our results provide a key insight on how climate change drives vegetation responses.

\section{Acknowledgements}

The authors thank HD Adams, PC Beeson, J Davison, KA Dayem, MH Ebinger, JM Fair, MO Gard, KL surements spanning a range of environmental conditions showed a similar relationship between photosynthesis and plant water potential, including the zero assimilation point (Lajtha and Barnes 1991). Second, the plant water potential associated with zero assimilation in piñon is the same as that observed at sites across the region and for other periods of time (Williams and Ehleringer 2000). Third, other studies have observed minimum values of plant water potential for $P$ edulis close to its zero assimilation threshold (West et al. 2007). With respect to the role of infestation by bark beetles, previous research has shown that susceptibility to infestation is interrelated with plant water stress (Allen and Breshears 1998; Breshears et al. 2005; Shaw et al. 2005). Our results are consistent with that perspective, and add to it in documenting the magnitude of water stress that occurred prior to observable infestation and subsequent tree mortality.

Our observations directly document plant water stress leading to widespread mortality; in contrast, only precipi-
Goddard, L Graumlich, CE Heil, SR Johnson, SA Kammerdiener, CP Kempes, SA Kurc, RJ Lucero, SN Martens, LJ Martinez, KD Reid, JA Salazar, N Stephanson, JC Villegas, H Wei, and BP Wilcox for data collection and discussion comments. Support was provided by Los Alamos National Lab (Environmental Restoration and LDRDDR), the National Science Foundation (NSF\# DEB0443526; EAR-9876800), Arizona Agricultural Experiment Station (\#126-580), Bio-sphere 2 (B2 Earthscience via Philecology Foundation), DOE NICCR (Western Region; DE-FC02-06ER64159), and Office of Science (BER), Department of Energy Grant \# DE-FG0207ER 64393. Data (monthly pre-dawn plant water potential values) provided in WebPanel 1.

\section{References}

Allen CD. 2007. Interactions across spatial scales among forest dieback, fire, and erosion in northern New Mexico landscapes. Ecosystems 10: 797-808. 
Allen CD and Breshears DD. 1998. Drought-induced shift of a forest-woodland ecotone: rapid landscape response to climate variation. P Natl Acad Sci USA 95: 14839-42.

Breshears DD. 2008. Structure and function of woodland mosaics: consequences of patch-scale heterogeneity and connectivity along the grassland-forest continuum. In: Van Auken OW (Ed). Western North American Juniperus communities. Ecological studies series. New York, NY: Springer.

Breshears DD and Allen CD. 2002. The importance of rapid, disturbance-induced losses in carbon management and sequestration. Global Ecol Biogeogr 11: 1-5.

Breshears DD, McDowell NG, Goddard KL, et al. 2008. Foliar absorption on intercepted rainfall improves woody plant water status most during drought. Ecology 89: 41-47.

Breshears DD, Myers OB, Johnson SR, et al. 1997. Differential use of spatially heterogeneous soil moisture by two semiarid woody species: Pinus edulis and Juniperus monosperma. J Ecol 85: 289-99.

Breshears DD, Cobb NS, Rich PM, et al. 2005. Regional vegetation die-off in response to global-change-type drought. P Natl Acad Sci USA 102: 15144-48.

Gitlin AR, Sthultz CM, Bowker MA, et al. 2006. Mortality gradients within and among dominant plant populations as barometers of ecosystem change during extreme drought. Conserv Biol 20: $1477-86$.

Hacke UG, Stiller V, Sperry JS, et al. 2001. Cavitation fatigue. Embolism and refilling cycles can weaken the cavitation resistance of xylem. Plant Phys 125: 779-86.

IPCC (Intergovernmental Panel on Climate Change). 2007. Climate change 2007: impacts, adaptation and vulnerability. Contribution of Working Group II to the fourth assessment report of the Intergovernmental Panel on Climate Change. New York, NY: Cambridge University Press.

Jentsch A, Kreyling J, and Beierkuhnlein C. 2007. A new generation of climate-change experiments: events, not trends. Front Ecol Environ 5: 365-74.

Lajtha K and Barnes FJ. 1991. Carbon gain and water-use in pinyon pine-juniper woodlands of northern New Mexico - field versus phytotron chamber measurements. Tree Physiol 9: 59-67.

Linton MJ, Sperry JS, and Williams DG. 1998. Limits to water transport in Juniperus osteosperma and Pinus edulis: implications for drought tolerance and regulation of transpiration. Funct Ecol 12: 906-11.

MA (Millennium Ecosystem Assessment). 2005. Ecosystems and human well-being: general synthesis. Washington, DC: World Resources Institute.

McDowell N, Pockman WT, Allen C, et al. 2008. Mechanisms of plant survival and mortality during drought. Why do some plants survive while others succumb to drought? New Phytologist 178: 719-39.

NRC (National Research Council). 2007. Understanding multiple environmental stresses. Washington, DC: National Academies Press.

Pockman WT, Sperry JS, and Oleary JW. 1995. Sustained and significant negative water-pressure in xylem. Nature 378: 715-16.

Shaw JD, Steed BE, and DeBlander LT. 2005. Forest inventory and analysis (FIA) annual inventory answers the question: what is happening to pinyon-juniper woodlands? J Forest 103: 280-85.

Sperry JS, Adler FR, Campbell GS, and Comstock JP. 1998. Limitation of plant water use by rhizosphere and xylem conductance: results from a model. Plant Cell Environ 21: 347-59.

Sperry JS, Hacke UG, Oren R, and Comstock JP. 2002. Water deficits and hydraulic limits to leaf water supply. Plant Cell Environ 25: 251-63.

van Mantgem PJ and Stephenson NL. 2007. Apparent climatically induced increase of tree mortality rates in a temperate forest. Ecol Lett 10: 909-16.

West AG, Hultine KR, Jackson TL, and Ehleringer JR. 2007. Contrasting hydraulic strategies explain differential summer moisture use of Pinus edulis and Juniperus osteosperma. Tree Physiol 27: 1711-20.

Williams DG and Ehleringer JR. 2000. Intra- and interspecific variation for summer precipitation use in pinyon-juniper woodlands. Ecol Monogr 70: 517-37. 